\title{
Methods of Future Science Teachers Training to Use Smart-Technologies in the Professional Activity
}

\author{
DOI: $10.46932 / \operatorname{sjdv} 3 n 1-038$
}

Received in: Dec 30st, 2021

Accepted in: Jan 1th, 2022

\author{
Alla V. Stepanyuk \\ D.Sc. of Pedagogical Sciences, Professor, Ternopil Volodymyr Hnatiuk National Pedagogical \\ University, 2 Maxyma Kryvonosa str., Ternopil, 46027. Ukraine. \\ E-mail: alstep@tnpu.edu.ua
}

\section{Liudmyla P. Mironets}

PhD of Pedagogical Sciences, Associate Professor, Sumy A. Makarenko State Pedagogical University, Sumy, 40002, Ukraine.

E-mail: mironets19@gmail.com

\section{Tetiana M. Olendr}

$\mathrm{PhD}$ of Pedagogical Sciences, Associate Professor, Ternopil Volodymyr Hnatiuk National Pedagogical University, 2 Maxyma Kryvonosa str., Ternopil, 46027, Ukraine.

E-mail: olendr@tnpu.edu.ua

\section{Ivan M. Tsidylo}

D.Sc. of Pedagogical Sciences, Professor, Ternopil Volodymyr Hnatiuk National Pedagogical University, 2 Maxyma Kryvonosa str., Ternopil, 46027, Ukraine, 46027.

E-mail: tsidylo@tnpu.edu.ua

\begin{abstract}
The article deals with one of the possible ways of modernization of pedagogical education in Ukraine in order to train teachers of the new generation and to provide conditions for the formation and development of modern alternative models of teachers' professional and personal growth on the principles of SMARTeducation concept. The problem of future science teachers training to use SMART-technologies in the professional activity as the condition for realization of the SMART-concept in education is actualized. The advantages of SMART-technologies use in the study of objects and phenomena of wildlife have been substantiated. They allow the formation of holistic thinking of both students and schoolchildren by combining figurative and logical thinking and strengthen the emotional and value perception of wildlife objects. Methods of formation of future science teachers' readiness to use SMART-technologies in the educational process, which involves the realization of a dual goal: the formation of the ability to use the resource SMART-concept in education to implement their own lifelong education and providing quality professional activities during teaching natural sciences school course have been highlighted. The foundation of the proposed methodology constitutes module "Methods of using SMART-technologies", which is a component of the discipline "Methods of Biology teaching". The content and means of its studying by students, tasks for the organization of independent work, tests, criteria and indicators of the level of students' abilities and skills formation to use the SMART-complex (motivational-value, cognitive, activity-constructive, reflexive and evaluative) have been developed. The effectiveness of the proposed methods on the basis of determined criteria has been proved experimentally.
\end{abstract}


Keywords: education, SMART-technologies, schoolchildren/students, future science teachers, methods of teaching, professional training, Biology.

\section{INTRODUCTION}

\subsection{THE PROBLEM STATEMENT.}

Reforms in education in the XXI century put forward new demands before the teachers. A teacher who thinks freely and actively, who foresees the results of his activities and accordingly models the educational process is a guarantor of solving the tasks set before the school. The quality of teaching staff is the most important component of the educational system. Realization of all other components of this system directly depends on the human resources with which it is provided. Teacher are responsible for the implementing new generation educational programs based on advanced pedagogical technologies, they are assigned the mission of preparing the younger generation for life in the future and educating a person with modern thinking, able to successful self-realization in life. Thus, the tasks of modern education vary in accordance with the requirements of the century by finding new technologies and modernizing the educational environment.

Present realities made us move to SMART-education concept. It involves complex modernization of all educational processes, as well as methods and technologies used in them. SMART-education means new knowledge and ideas generation, development of SMART-environment, SMART-society - an intellectual environment of people who are specially trained to implement the latest ideas and concepts. A lot of countries in the world, namely Korea, Japan, Australia, the Netherlands have claimed the SMART idea as a national idea of the whole society. According to UNESCO, the use of SMART-technologies provides an opportunity to significantly expand and improve learning opportunities, in particular in higher education institutions.

\subsection{THE ANALYSIS OF RECENT STUDIES AND PUBLICATIONS.}

The analysis of literary sources allows to confirm that understanding of SMART in the area of education ranges from the use of smartphones and other similar devices to deliver information to schoolchildren/students to the formation of an integrated intelligent virtual learning environment, including SMART devices. Our study is based on the complex considering of this problem.

Historically, the transformation of educational technologies has taken place within the chain: traditional - distance - e-learning - new information and communication technologies (Smart). The use of SMART-technologies is aimed at achieving the following goals in the learning process: S (Self Directed) - providing opportunities for self-determination of what to learn and effective organization of 
self-learning; M (Motived) - motivation of active cognitive activity; A (Adaptive) - adapting the methods, place and time for learning for a specific subject who wants to gain educational services; R (Resource Free) - providing free access to educational resources; T (Technology Embedded) - permanent support of the learning process with modern technologies. V. Tykhomyrov briefly interprets the abbreviation SMART as: $\mathrm{S}$ - self-managed, $\mathrm{M}$ - motivated, $\mathrm{A}$ - adapted, $\mathrm{R}$ - resource-provided, $\mathrm{T}$ - technological [1].

According to O. Semenikhina [2, p. 42], the concept of SMART-education correlates with the latest educational trends voiced by FORBS magazine: distance education is becoming a leader in educational technologies - video lessons on YouTube or other services are mega-popular and in demand amongst the younger generation; personalization of learning - individual psychological characteristics of a person should become the basis for individual educational programs; gamification (introduction of game technologies in non-game situations) - reward technologies for what has been done can help to increase the learning motivation and improve its quality; interactive textbooks that should radically change the "traditional" presentation and interpretation of educational material; learning with the help of video games is a unique opportunity to provide knowledge about the real world through an interactive immersion in the virtual world.

The concept of SMART in terms of education contributes to the emergence of technologies such as SMART board, SMART screens, the Internet access from anywhere. Each of these technologies allows to building the process of content development, its delivery and updating in a new way. It is possible to learn not only in the classroom, but also at home and in any place: public places, such as museums or cafes. The main element which binds the educational process is active educational content, on the basis of which unified repositories are created, which allow to remove the time and space limits. Thus, SMARTeducation involves the use of smartphones, tablets, interactive whiteboards, other devices with Internet access, as well as all kinds of educational programs and applications for educational aims.

The scientists $[1,2,3,4,5]$ consider that the goal of SMART-education is to ensure the most effective learning process by transferring the educational process to the electronic environment. Such approach provides an access to knowledge to anyone, expands the boundaries of learning. First of all, SMART-education provides flexibility (a large number of sources, maximum media diversity, the ability to quickly and easily adjust to the level and needs of the listener). It involves an active exchange of experiences and ideas, personalization of the course, saving time for refinement (editing existing material instead of creating it from the beginning).

The positive aspects of the use of SMART-technologies in the educational process include: the possibility of their use in the teaching of various disciplines; high efficiency of knowledge acquisition; increasing interest in learning among schoolchildren and students; modern technologies and understanding and perception of them as a natural component of young people, which makes their lives a 
convenient tool for creative development; ease of combining SMART-technologies with a communicative approach [6].

The analysis of literature sources proved that the problem of using SMART-technologies in the educational process has received some elaboration in the scientific achievements of such scientists as $\mathrm{V}$. Abramov (2007), G. Ahmetova (2013), H. Bonch-Bruievych (2007), V. Bykov (2013), K Bucher, Yu. Hapon, L. Ivanenko, O. Zubova, Zh. Karaev (2013), R. Kozma (7) T. Kosenko (2007), A. Kushnir (2020), S. Muhambetzhanova (2013), T. Pozdniakova (2018), S. Pudova (2018), V. Tihomirov (2011), O. Semenikhina (2015), M. Sharples (2007) and others. Thus, modern SMART-technologies as a means of innovation and a factor of information development of society, which provide the transformation of the teacher from a translator of information to a facilitator of communication in the process of combined activities with students, have been analyzed in the works of A. Kushnir (2020) [5]. The effectiveness of the use of SMART-technologies in the educational process has been theoretically substantiated and it has been proved that the use of SMART-technologies diversifies the educational process, increases cognitive interest and motivation of students at the expense of visible, real result of their foreign language daily professional activity, allows to expand considerably traditional educational technologies, optimizes expenses on logistics, as well as provides access to a new level of quality of educational services. O. Semenikhina (2015) states in her studies that the use of SMART approach in the preparation and development of educational materials testifies the learning process with the use of technological innovations. It provides an opportunity to obtain professional competence on the basis of a systemic multidimensional vision and study of disciplines, taking into account their multifaceted nature and continuous updating of content [2]. At the same time it is universally recognized that future teachers should be fluent in using the latest information technologies, both at the technical and theoretical levels, through which the solution of any socio-pedagogical problems will be methodically correct, based on acquired knowledge, skills and abilities.

The issues concerning the use of information devices in the process of Biology school course studying were described in our previous paper [14]. However, the problem of future natural sciences teachers training for the introduction of SMART-technologies into the process of professional activity has not been properly studied yet. The goal of our study is to develop a methodology for forming the future teachers' readiness to use SMART-technologies in the process of Biology school course studying and verify its effectiveness.

The research was realized through the following tasks:

1. To identify the specifics of the SMART-technology use in the process of Biology school course studying.

2. To develop a methodology for forming the future science teachers' readiness to use SMART- 
technologies in professional activities.

3. To substantiate the criterion apparatus for determining the level of future science teachers' readiness to use SMART-technology in educational process.

\section{RESEARCH METHODS}

To achieve the abovementioned goal and tasks, a number of methods have been used, namely: theoretical - comparative analysis to find out different views on the problem, identify areas of study; modeling to develop a methodology for forming the future science teachers' readiness to use SMARTtechnologies in professional activities; designing - to develop a criterion apparatus of the research; systematization and generalization to formulate conclusions and recommendations for improving the educational process during future natural sciences teachers training for the introduction of SMARTtechnology in educational process; empirical - generalization of pedagogical experience, scientific observation, interviews, content analysis, questionnaires in order to determine the state of implementation of the problem in practice and to develop the content of experimental teaching methodology; pedagogical experiment, which provided verification of the effectiveness of the proposed methodology.

Experimental research has been carried out on the basis of Ternopil V. Hnatiuk National Pedagogical University and Sumy A. Makarenko State Pedagogical University. Effectiveness of the proposed methodology was checked during the forming experiment. Forming experiment lasted for two years (2019-2020 and 2020-2021 academic years) in the process of professional and methodical training of future natural sciences teachers. It involved 38 future Biology teachers, who are now students of the second (master's) level of higher education. The goal of the forming experiment was to test the effectiveness of the developed methodology for forming the future science teachers' readiness to use SMART-technologies in professional activities.

\section{THE RESULTS AND DISCUSSION}

Preparatory stage, the aim of which was to determine the peculiarities of the SMART-technologies use in the process of Biology study preceded the development of an experimental methodology of forming the future natural sciences teachers' readiness to use SMART-technologies in professional activities. To do this, we analyzed the following factors:

- the essence of SMART-technologies and the expediency of their use in the educational process of secondary schools and universities;

- the peculiarities of the object of biological cognition (plant, animal organisms and humans);

- the content of future science teachers professional and methodological training;

- the content of Biology school course program. 
The results of the conducted analysis showed that the peculiarities of the SMART-technologies use in the process of Biology school course studying are related to the object of its study - integral systems of wildlife in their hierarchical relationships and interdependencies, as well as the necessity to form emotional and value attitude of schoolchildren to the world of nature on the basis of bioethics. Due to emotional and value as well as figurative perception SMART-technologies make it possible to penetrate into the microworld of the cell, to model life processes in systems of different levels of organization, to demonstrate the manifestation of general laws of nature at the level of sensory-figurative perception, to reveal the beauty of wildlife in its uniqueness, diversity and interdependence of its systems, to highlight its self-value, universality and significance in our daily life.

Considering these peculiarities, as well as: the main objectives of training a highly qualified specialist who will show a desire for self-improvement and self-realization in his professional activity through a certain manifestation of self-efficacy, self-reflection and self-correction; expediency and need for integration of educational and self-educational activities in higher education; organization of research, dialogue, discussion, creative nature of relations of subjects of training in all paradigmatic variations of interaction with the help of SMART-technologies: "teacher - student", "teacher - students", "student student", "student - students", “student - schoolchild", “student - schoolchildren", "student - student", we have developed a methodology of forming the future science teachers readiness to use SMARTtechnologies in professional activities.

The proposed methodology involves a combination of the process of future teachers' general and professional competencies formation through the use of SMART-technologies in the teaching of disciplines (skills are formed by imitation) and purposeful activities to train future science teachers to use SMART-technologies in professional activities. Herewith, students have an opportunity to study disciplines using electronic materials, watch lectures online or offline, sit tests, participate in telecommunication projects, share experience, improve their professional level, spend more time for scientific experiments, save time, etc. They can do everything independently or using the technology of "flipped learning".

The basis of the methodology of forming the future science teachers readiness to use SMARTtechnologies in professional activities is the subject "Methods of Biology teaching", the structure of which includes the study of a special module (30 academic hours) on SMART-technologies. It comprises 4 academic hours of lectures and 8 academic hours of practical classes, as well as 18 academic hours of independent work. In particular: 
Lecture №1. SMART-technologies and and their main possibilities in preparation for a Biology lesson. LEARNING APPS: features, functions, advantages and disadvantages.

The objective of the class: to get acquainted with the world experience of using SMARTtechnologies and the current state of their development in Ukraine; to identify the main possibilities of using information technologies in education; to provide a characteristic of the LEARNING APPS Internet resource, to single out its main functions and didactic possibilities.

Lecture №2. Modern possibilities of mobile application. The use of video-content in the pedagogical activities of a teacher. YouTube as a modern video hosting.

The objective of the class: to get acquainted with the concept of mobile learning; to determine the role of mobile applications in preparing and conducting a Biology lesson; to single out the kinds of video content in pedagogical activities and platforms for their application.

Now we would like to present description of the methods of conducting practical classes.

Practical class №1.

Topic: Mobile application as a part of modern Biology lesson.

Objective: to consolidate students' knowledge of the use of mobile applications at Biology lessons; to make actual the basic principles of working with a mobile application; to conduct a lesson on the use of mobile learning; lesson analysis. The following issues should be considered: peculiarities of the use of mobile applications at Biology lessons; basic features of digital communication; platforms for working with mobile applications.

Students are given the following tasks for classroom independent work: presentation of a mobile application for work at a Biology lesson, the main educational possibilities, advantages and disadvantages of the work; compiling of the table arranging columns; mobile application, advantages and disadvantages of use, forms of work.

Tasks for out-of-class work: to prepare a lesson plan on the topic "The structure of modern ecology and its place in the system of sciences" using four exercises from the LEARNING APPS Internet resource at different stages of the lesson; compile and fill in the table (using 5 templates from the LEARNING APPS program) by columns: the name of the template, instructions for creating the exercise, form of work, example of use.

\section{Practical class №2.}

Topic: LEARNING APPS Internet resource in future natural sciences teacher preparation to the lesson. 
Objective: to consolidate students' knowledge on creating tasks for Biology lessons on the LEARNING APPS online platform; to get acquainted with various templates and additional functions of the resource; to conduct a lesson using SMART-technologies; to carry out analysis and self-analysis of the lesson. The following issues should be considered: main possibilities and functions of the LEARNING APPS Internet resource; types of exercises on the platform, their didactic possibilities; checking of outof-class work from the previous lesson.

Students are given the following tasks for classroom independent work: conducting a lesson on the topic "The structure of modern ecology and its place in the system of sciences" using four exercises from the LEARNING APPS Internet resource at different stages of the lesson; to carry out self-analysis of the lesson; advantages and disadvantages of the lesson; group analysis of the lesson.

Tasks for out-of-class work: to prepare a lesson plan on the topic "Populations and their characteristics"; to create accounts for schoolchildren before the lesson using the LEARNING APPS platform and check their readiness to use them at a Biology lesson; to create four different tasks in the Internet resource for doing exercises independently and send them to schoolchildren's personal accounts; to write down advantages and disadvantages of using the LEARNING APPS Internet resource in preparation for a Biology lesson.

Practical class №3.

Topic: Main functional potentialities of LEARNING APPS. Peculiarities of creating one's own class in the Internet resource.

Objective: to consolidate students' knowledge on creating tasks for Biology lessons on the LEARNING APPS online platform; technology of creating work accounts for schoolchildren; development of classroom management skills, statistics and general information; conducting a lesson using SMART-technologies; to carry out analysis and self-analysis of the lesson.

The following issues should be considered: basic requirements for creating exercises at the stages of generalization of material and systematization of knowledge using the LEARNING APPS platform; technology and instructions for creating one's own class, accounts for it and statistics; checking students' out-of-class work from the previous lesson.

Students are given the following tasks for classroom independent work: conducting a lesson on the topic "Populations and their characteristics"; analysis of the fulfilled tasks, their characteristics, didactic possibilities, feasibility of using; to carry out self-analysis of the lesson; advantages and disadvantages of the lesson; group analysis of the lesson. 
Tasks for out-of-class work: to prepare a lesson plan on the topic "Biogeocenosis and its structure"; to prepare video content on the topic before the lesson; to create two new tasks in the LEARNING APPS Internet resource; to send assignments to the schoolchildren's accounts; to choose tasks on the ecological subject on this topic using a mobile application; to carry out a written analysis of the "Statistics" function; to describe the technology of using this application, the main features and advantages; provide a photo of the statistics from the previous lesson.

Practical class №4.

Topic: SMART-technologies as a future teacher assistant in preparation to Biology lessons.

Objective: to consolidate students' knowledge on the use of SMART-technologies in the future teacher's professional activities; to compare information technologies; to develop a modern lesson with an approach to working with SMART tools; to analyze the work and to carry out self-analysis of the results; to conduct questionnaires and testing to identify the formed students' knowledge.

The following issues should be considered: checking students' out-of-class work from the previous lesson; to carry out the comparative analysis of SMART-technologies.

Students are given the following tasks for classroom independent work: conducting a lesson on the topic "Biogeocenosis and its structure"; to carry out self-analysis of the lesson; advantages and disadvantages of the lesson; group analysis of the lesson.

Tasks for out-of-class work: responding to a questionnaire with the aim to find out the effectiveness and feasibility of using SMART-technologies in preparation for Biology lessons; passing tests to identify the formed knowledge, skills and abilities in the use of SMART-complex and mastering the studied material.

With the aim of consolidation the acquired knowledge the students did corresponding independent work, developed lesson plans, created their own exercises in the LEARNING APPS Internet resource, reviewed the learning opportunities of mobile applications, carried out analysis and self-analysis of the work and created their own video lessons to implement them in video hosting for distribution and use in own educational practice.

The topic "Creating your own video lesson" was given to students for independent study. The aim of this activity was: to consolidate knowledge on creating one's own content; master the work with modern technologies; to form students' ability to create independently their own scientific material; to check the level of skills mastering acquired during the study of the module.

There were several requirements how to perform the task: a fragment of the lesson should be at least 8 minutes; the tasks from the LEARNING APPS Internet platform should be used during the lesson; a part of any stage of the lesson should be conducted; the theoretical material of the video must correspond to reality; the video can be used as part of a lesson; there should be creative and problematic tasks. 
Examples of some programs for video editing were given: inSchot. Sony Vegas Pro 15.0, Sony Vegas Pinacle. KineMaster, Movavi, Film Marcer, etc.

Questionnaires and tests were created to find out the effectiveness of the SMART-complex and the formation of key competencies in the use of information technologies.

\subsection{EXAMPLE OF A QUESTIONNAIRE FOR STUDENTS.}

- In your opinion, how effective is the use of SMART-technologies at biology lessons? For answers choose numbers from 1 to 5 .

- How convenient and understandable was it for you to use a variety of technologies in preparation for biology lessons? For answers choose numbers from 1 to 5.

- During which type of lesson (acquisition of new knowledge, abilities and skills formation, reviewing and consolidation of knowledge, generalization, testing and correction of knowledge, combined) is the use of SMART-complex (LEARNING APPS, mobile application, YOU TUBE and other video hosting) the most efficient? Place numbers from 1 to 6 , where 1 is the most efficient and 6 is the least.

- Have you been acquainted with SMART-technologies before? (Yes/No)

- In your opinion, what is more universal when preparing for a lesson? For answers choose numbers from 1 to 3 , where 1 is the most universal, 3 is the least universal.

LEARNING APPS -; mobile application -; YOU TUBE and other video hosting -.

- - How convenient is it to work using LEARNING APPS function "My Classes"? For answers choose numbers from 1 to 5 .

- - In your opinion, what stage of the lesson (actualization of basic knowledge and life experience of students, motivation of learning activities, learning new material, generalization and systematization of knowledge, lesson results, home task) is the most appropriate for the use of different technologies (LEARNING APPS, mobile application, YOU TUBE and other video hosting)? For answers choose numbers from 1 to 6 , where 1 is the most appropriate, 6 is the least appropriate.

\subsection{EXAMPLES OF THE TASKS FOR TESTING STUDENTS.}

Special blocks of theoretical questions on the studied material were developed to test students in order to check the level of competencies formation.

In general, the test includes 20 open-ended questions, which are divided into four blocks. Each question is evaluated from 1 to 5 points. In total, each student can get 100 points for the answers. We have developed special criteria for evaluating responses: 
- 1 point - acquisition of theoretical knowledge is very poor, no completeness of the answer, no examples;

- 2 points - acquisition of theoretical knowledge is very poor, the answer is structured and logical, the student gives basic examples;

- 3 points - acquisition of theoretical knowledge is at the middle-level, the answer is structured and logical, the student gives examples based on his own experience of the work with information technologies;

- 4 points - acquisition of theoretical knowledge is at the sufficient level; the answer is clear, structured and logical; the student gives examples based on his own pedagogical activity and personal developments, the student analyses and makes conclusions;

- 5 points - acquisition of theoretical knowledge is at the high level; the answer is structured, logical and reliable; the student is able to answer problematic questions and finds ways to solve them; gives specific examples of the use of information technologies, which he used in preparation for the lessons; critical thinking, analysis and conclusions.

Block 1. Mobile application as a part of contemporary Biology lesson.

- Characterize mobile applications and their role in the teacher's pedagogical activity.

- M-learning: for/against.

- Give specific examples of mobile applications and topics of lessons where they can be used?

- Is it appropriate to use mobile applications during distance work with schoolchildren? In what forms of work do you think M-learning is most effective?

Block 2. LEARNING APPS Internet resource in preparation of the future natural sciences teacher to the lesson.

- Name the main advantages and disadvantages of working with the LEARNING APPS Internet resource.

- Characterize the main designation of the LEARNING APPS platform at Biology lessons.

- Present a complete description of the list of LEARNING APPS templates. Create categories by which you could categorize the exercises and single out a series of highly versatile exercises.

- In your opinion, is it possible to combine mobile learning with the technology of the LEARNING APPS platform?

Block 3. Main features of LEARNING APPS. Peculiarities of creating one's own class in the Internet resource.

- Present a complete description of the main features of LEARNING APPS. 
- Describe instructions for creating one's own class using the additional function of the LEARNING APPS platform.

- Statistics as an assistant in pedagogical work of the future teacher! Do you agree with this statement? Justify and give examples.

- Conduct a comparative analysis of the use of the LEARNING APPS Internet resource and different types of mobile applications at Biology lessons.

Block 4. SMART-technologies as the future teacher's assistant in preparation for Biology lessons.

- Significance of SMART-technologies in preparation and conducting Biology lessons.

- Contemporary video hosting as a part of the educational process! Do you think that video training will become a part of the teacher's work in the future?

- Advantages and disadvantages of using video training and video platform in the work of a Biology teacher.

- Develop clear requirements for the creation of video content for educational purposes to conduct Biology lessons.

The data objectivity obtained during the forming experiment is ensured by the special conditions of its conducting:

- 38 students majoring in specialty 014 Secondary education (Biology and human health. Chemistry) took part in the pedagogical experiment.

- The best possible acquisition of theoretical knowledge in natural sciences by the students (concepts, laws, regularities, their use in preparation for the lessons).

- Sufficient level of modern information technologies mastering (PC, Internet, mobile applications, etc.).

- Development of the author's program of mastering SMART-technologies (lectures, practical classes, independent work, literature, tests and questionnaires), which increases the reliability of the obtained results.

- Students were assessed in accordance with the course plan "Methods of Biology teaching".

The criteria for identifying the level of students' abilities and skills formation to use the SMARTcomplex have been developed.

The scheme of students' knowledge and skills analysis during the pedagogical experiment:

- Identifying the initial state of students' abilities and skills level.

- Identifying the level of students' intellectual abilities and learning outcomes formation through observation, work analysis, assessing the students' readiness for practical classes, mastering the theoretical basis, passing special tests and questionnaires. 
- Identifying the change in the level of students' readiness to use SMART-technologies in teaching

- Confirmation of the effectiveness of the SMART-technologies use at biology lessons using methods of statistical processing.

At the beginning of the pedagogical experiment we determined the level of students' understanding of the concept of "SMART-education" and their understanding of the role of information technology in pedagogical activities. The students were offered to answer the question "Have you heard of SMART-technologies before working with them?" Analysis of the results proved that $63 \%$ of the respondents (24 students) were partially familiar with SMART-education technologies before and $37 \%$ (14 students) began to use and got acquainted with them for the first time during experimental training.

During the pedagogical experiment students were taught according to the experimental methodology of forming the future natural sciences teachers' readiness to use SMART-technologies. Students were taught how to use an interactive whiteboard SMART Board and its various functions. Special exercises were developed using the LEARNING APPS Internet resource in preparation for lessons and then they were used during all the stages of the lesson. Students downloaded different mobile applications at various world software platforms and added parts of mobile teaching to the lesson plans, applying and testing the effectiveness at different stages of the lessons. Future science teachers performed tasks of independent work, where they created their own video lessons and considered the main possibilities of modern video hosting and its role in the educational process currently and prospects for the future. Performing tasks and during the preparation for lessons as well as during teaching practice students developed their own lesson plans, did author's tasks on the LEARNING APPS platform, introduced mobile learning technology in educational activities, recorded videos, passed tests, performed independent work, for which they received a certain number of points. Students' learning outcomes were assessed according to the criteria of the corresponding course, and the formation of intellectual skills according to three levels (middle, sufficient and high).

The use of SMART-technologies during the development of lesson plans contributed to increasing of students' activity and motivation to work, interest in teaching activities became noticeable and the level of preparation for lessons and works in writing changed. Students learned to use a SMART Board, create their own accounts in the LEARNING APPS Internet resource, author's exercises on this platform, personal video lessons, learned to use various video editing programs, improved personal skills of lesson planning and analyzed the effectiveness of information technologies use.

After the completing the training according to the experimental methodology, the students were offered to determine the most effective information technology in terms of its implementation in teaching. To do this, they were asked to determine the most effective technology considering their own experience by ranking them from 1 to 3 . The results of the study showed that $41.3 \%$ of the surveyed students chose 
the use of tasks from the LEARNING APPS Internet resource at Biology lessons as the most effective technology. Various video lessons as an effective tool in teaching were chosen by $35.5 \%$ of future teachers. The third place was given to the technology of mobile teaching in the pedagogical activities. $23.3 \%$ of students (future natural sciences teachers) chose this technology.

In the process of preparation for the lesson, modeling its plan, it is important to understand for what type of lesson you need to use SMART-technology. The students were offered to choose the most optimal type of lesson for each information technology. Future natural sciences teachers had to rate from 1 to 6 how it is effective the use of a particular technology at different types of lessons. Obtained results were presented in the table and the arithmetic mean of the index was defined (Fig. 1).

Fig. 1. Efficiency of the SMART-complex use at the lessons of different types

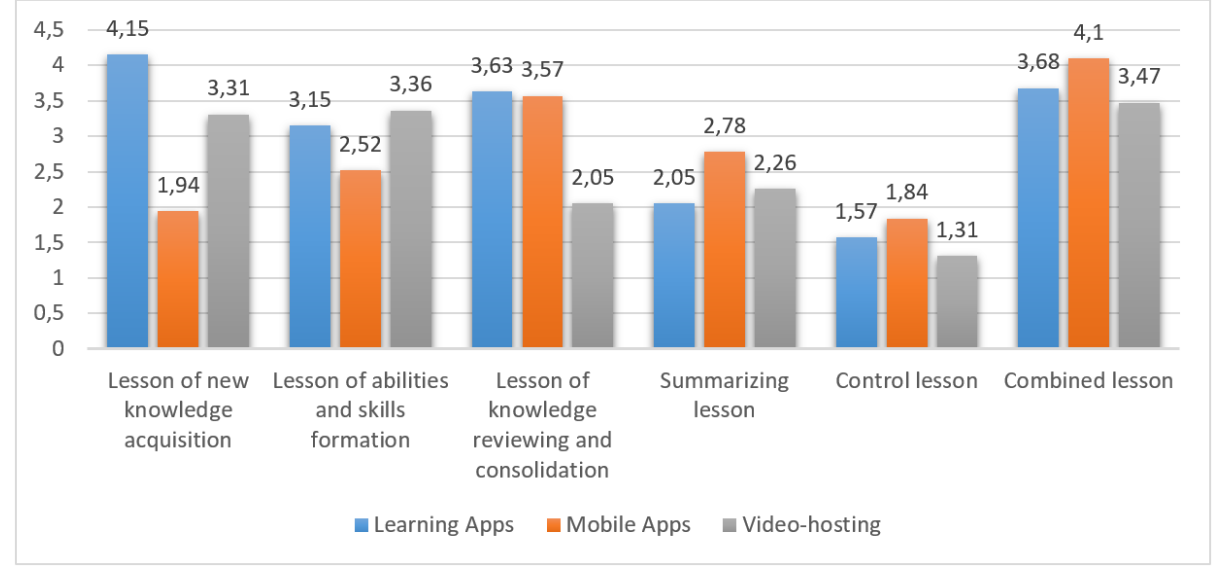

We found that the technology of using the LEARNING APPS Internet resource was the most effective when it was used at the lessons of new knowledge acquisition. Students' response mean was 4.15. The least effective was the use of this information platform at the control lesson (1.57). Students recommend using of mobile learning at the combined lesson (4.10). The least effective and appropriate was the use of mobile applications at control lessons (1.84). The use of video materials at Biology lessons was the most effective during the combined lesson (3.47) and at the lesson of abilities and skills formation (3.36). Video hosting was less used at the control Biology lessons (1.31).

In the process of preparation for the lesson, it is important for the teacher to plan his work in the best possible way and divide the lesson into its stages most efficiently. Future teachers were offered to prioritize from 1 to 6 choosing the most effective stage of the lesson for the use of the SMART-complex technology. All the answers were presented in the table and the priority ranking mean was defined. These results are given in Fig. 2. 
Fig. 2. Efficiency of the SMART-complex use at different stages of a lesson

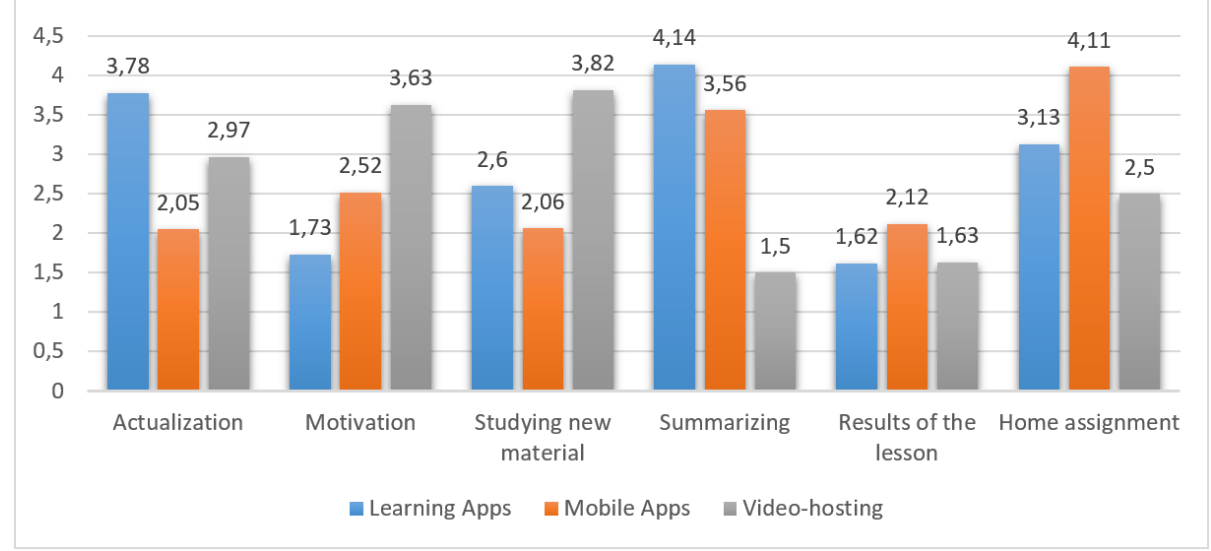

At determination the efficiency of the LEARNING APPS Internet platform use at Biology lessons it was found that the most optimal use of technology was at the stage of summarizing of students' knowledge (response mean is 4.1) and the lowest mean of technology choice was given to the stage results of the lesson (1.57). The use of mobile applications by future specialists at Biology lessons is recommended and has the highest rate during the stage of home assignment and independent work of schoolchildren (4.15).

The work with the mobile learning technology is not effective at the stage of knowledge actualization and studying new material with the same response coefficient of 2.05. During the preparation of a lesson plan, the use of video-learning was noticed at the stage of studying new material and schoolchildren's knowledge, skills and abilities formation with the index of 3.73. The least use of videohosting was observed at the stages of summarizing (1.52) and results of the lesson (1.68).

To determine the level of students' readiness to use SMART-technologies, we have developed the following criteria: motivational-value (awareness of the importance of mastering the theoretical foundations of information technology and prospects for their development, highlighting the main benefits of mobile learning in natural sciences teacher work, understanding the role and prospects of modern videohosting use in pedagogical activities and self-education), cognitive (understanding: the place of SMARTtechnologies in the educational process and methodology of their use in preparation for biology lessons; functional possibilities of electronic-interactive whiteboard for teachers at biology lessons), activityconstructive (creation of one's own account on the LEARNING APPS Internet platform, understanding and optimal mastery of all the functions of the Internet resource, the ability to create quality author's programs and technology of the own class with statistics to it in LEARNING APPS, the use of various platforms for downloading mobile applications, mastery of the methods of conducting a lesson using video materials and creating one's own fragment of the video lesson), reflexive and evaluative (the ability to analyze, draw conclusions, observe, compare and analyze the fulfilled work). 
Having analyzed the level of future teachers' readiness to use SMART-technologies after the pedagogical experiment, we drew a conclusion that $26.3 \%$ of students showed a low level, $31.5 \%$ of students showed a middle level, and $42.2 \%$ of students showed a high level (Fig. 3).

Fig. 3. Formed readiness of future Biology teachers to SMART technologies use

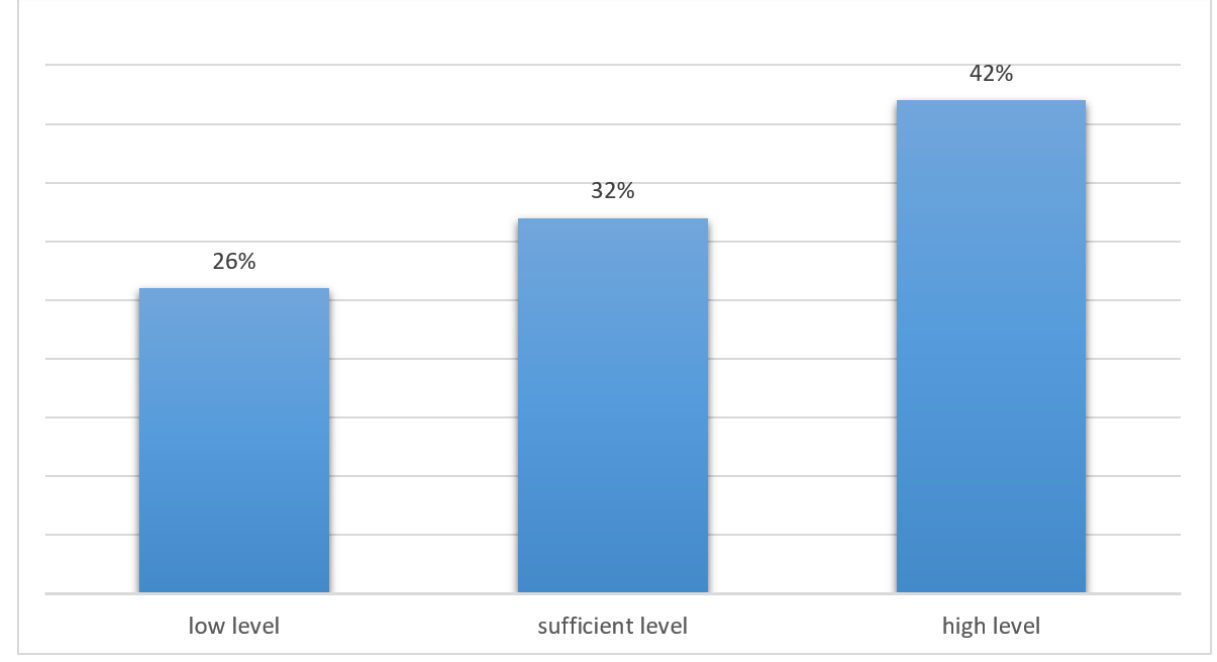

\section{CONCLUSIONS AND PROSPECTS FOR FURTHER RESEARCH}

Summing up the results of the conducted pedagogical experiment, we can conclude that the obtained data demonstrate the place of SMART-technologies in the pedagogical activity of the future teacher. Peculiarities of their application in the educational process are related to the object of study (cognition) at school. In our study it is integral systems of wildlife in their hierarchical relationships and interdependencies, as well as the necessity to form emotional and value attitude to the world of nature on the basis of bioethics.

In the course of future teachers training it is expedient to combine the process students' general and professional competencies formation through the use of SMART-technologies by teachers while teaching disciplines (in this case skills are formed by imitation) and special training of future teachers to use SMART-technologies in professional activities. Herewith, students have an opportunity to study disciplines using electronic materials, watch lectures online or offline, sit tests, participate in telecommunication projects, share experience, improve their professional level, spend more time for scientific experiments, save time, etc. They can do everything independently or using the technology of "flipped learning".

We have found that the technology of using the LEARNING APPS Internet resource is most effective when used at the lessons of new knowledge acquisition. M-learning and video materials are recommended to use at the combined lessons. The least effective and appropriate was the use of mobile applications at control lessons. In general, the use of SMART-technologies in the educational process of 
future teachers training, the formation of students' readiness to use them in professional activities increases the level of learning new material (it becomes more accessible and diverse), promotes increasing of interest and activity, the level of motivation to learning and forms cognitive interest to the learning process (cognition).

Widespread use of SMART-technologies in the process of future teachers' professional training will provide an opportunity to lay the foundation for successful professional activities and future career of higher education students.

The prospects for further study consist in finding the opportunities for the use of SMARTtechnologies in the formation of dichotomous, critical thinking of both students and schoolchildren, the formation of a holistic scientific worldview of students. 


\section{REFERENCES}

1.Tihomirov, V.P. The world on the way to Smart Education: new opportunities for development. Open education, no. 3, pp. 22-28 (2011).

2.Semenikhina, O.V. New paradigms in the field of education in the conditions of transition to SMARTsociety. Scientific Notes of Sumy State Pedagogical University named after A.S. Makarenko, no. 5, pp. 34-44 (2015).

3.Sharples, M. A Theory of Learning for the Mobile Age. London: The Sage handbook of E-Learning research. P.21 (2007).

4.SMART-technologies in Ukraine and in the world. Retrieved from: http://molodi.in.ua/smart-tehnolohiji/. Accessed 6 May 2021.

5.Smart Technology based Education and Training. Smart Digital Futures. Amsterdam: IOS Press BV. (2014).

6.Yakubov, S. \& Yakinin, Ya. SMART technologies and educational materials. Hi-Tech in school, no. 3-4, pp. 8-11 (2011).

7.Ahmetova, G.K., Karaev, Zh.A., \& Muhambetzhanova, S.T. Methodology of organizing advanced training of teachers in the context of introducing an e-learning system. Almaty: AO NCPK «Orleu». (2013).

8.Bonch-Bruevych, H.F., Abramov, V.O. \& Kosenko, H.I. Methods of using SMART Board in the study process. Kyiv, KMPU imeni B.D. Hrinchenka Publ., 102p. (2007).

9.Bykov, V.Yu. Mobile space and mobile oriented Internet-user's environment: features of model presentation and educational using. Information technologies in education, no. 17, pp. 9-37 (2013).

10.Kozma, R.B. The Influence of Media on Learning: The Debate Continues. School Library Media Research, no. 22, pp. 233-239.

11.Kushnir, A.S. SMART-technologies in education as a factor of social information development. Young Scientist, no. 3.1 (79.1) March, (2020). https://doi.org//10.32839/2304-5809/2020-79.1-10. Accessed 6 May 2021.

12.Pozdniakova, T. Using the Learning Apps service to create interactive didactic exercises for biology lessons. New pedagogical thought, no. 1, pp. 67-75 (2018).

13.Pudova, S.S. Using a mobile phone in the learning process. Sumy: Ministry of Education and Science of Ukraine. Sumy State Pedagogical University named after A. S. Makarenko. Physical and mathematical education: a scientific journal. no. 2 (16), pp. 97-101 (2018).

14.Alla V. Stepanyuk, Liudmyla P. Mironets, Tetiana M. Olendr, Ivan M. Tsidylo, Oksana B. Stoliar. Methodology of using mobile Internet devices in the process of biology school course studying. Cloud Technologies in Education 2019. Proceedings of the 7th Workshop on Cloud Technologies in Education (CTE 2019) Kryvyi Rih, Ukraine, December 20, P.535-547, (2019). http://ceur-ws.org/Vol2643/paper31.pdf. Accessed 6 May 2021. 